\title{
Resistência mecânica à penetração em sistemas de manejo do solo
}

\section{Mechanical strength to penetration in different management systems}

Gislayne Farias Valente ${ }_{4}^{1}$ Vicente Filho Alves Silva ${ }_{5}$; José Nilton da Silva ${ }^{3}$; Daiane Rodrigues da Silva Pinto $^{4}$; Jessivaldo Rodrigues Galvão ${ }^{5}$

${ }^{1}$ Mestranda em Agronomia, Universidade Federal Rural da Amazônia, Belém, Pará, gisllaynnefv@ hotmail.com; ${ }^{2}$ Doutor em Agronomia, Professor Adjunto II, Universidade Federal Rural da Amazônia, Parauapebas, Pará, vicente.silva@ufra.edu.br; ${ }^{3}$ Doutor em Agronomia, Professor Adjunto I, Universidade Federal Rural da Amazônia, Parauapebas, Pará, agrojns@yahoo.com.br; ${ }^{4}$ Engenheira Agrônoma, Universidade Federal Rural da Amazônia, Parauapebas, Pará, daiane.hidrotherm@gmail.com; ${ }^{5}$ Doutor em Agronomia, Engenheiro Agrônomo, Universidade Federal Rural da Amazônia, Belém, Pará, jessi.galvao50@gmail.com.

\section{N O T A}

Recebido: 06/08/2018

Aprovado: 29/11/2018

\section{Palavras-chave:}

Compactação

Máquina agrícola

Penetrômetro
Key words:

Compression

Agricultural Machinery

Penetrometer

\section{R E S U M O}

Os sistemas de manejo do solo podem resultar em alterações físicas no solo como a formação de camadas compactadas. Um dos atributos físicos mais adotados como indicativo da compactação do solo têm sido a resistência mecânica do solo à penetração, por apresentar relações diretas com o crescimento das plantas e por ser mais eficiente na identificação de estados de compactação do solo. Nesse sentido, objetivou-se avaliar a resistência mecânica do solo à penetração em dois sistemas de manejo do solo, por meio de utilização da técnica de penetrometria. O experimento foi realizado em área da Universidade Federal Rural da Amazônia, Campus de Parauapebas. O delineamento experimental utilizado foi inteiramente casualizado com dois tipos de manejo: sistema de plantio direto (SPD) e sistema de plantio convencional (SPC), com 40 repetições para cada tratamento. A resistência do solo à penetração $(\mathrm{RP})$ foi mensurada utilizando-se o Medidor Eletrônico de compactação do solo por pressão, modelo PenetroLOG - PLG 1020 da marca Falker, na profundidade de 0,00 a $0,40 \mathrm{~m}$ a qual foi subdividida em oito camadas de $0,05 \mathrm{~m}$ para avaliação. A adoção dos sistemas de plantio direto e plantio convencional ocasionaram oscilação na resistência mecânica do solo à penetração ao longo das camadas do solo. No SPC foi observada menor RP quando comparado ao outro tratamento, na profundidade 0,00 - 0,10 m. Diferente disso, no SPD as subcamadas de 0,15 - 0,25 m apresentaram menores valores de RP e maior umidade do solo. A partir da profundidade de 0,20 m ambos os sistemas apresentaram indicativo de camadas compactadas do solo.

\section{A B S T R A C T}

The diference soil management systems, can result in soil physical changes, such as the formation of compacted layers. One of the physical attributes most used as indicative of soil compact, has been the soil mechanical resistence to penetration, because it has direct relation with the growth of plants, and to be more efficient in identifying soil compaction stats. In this sense, the objective was evaluate the mechanical resistence to penetration in two soil management systens, by means of the use penetration technique. The experiment was carried out in the area of the University Federal Rural of Amazonia, Campus Parauapebas. The experiment design was completely randomized with two types of management no tillage system (NTS) and conventional plating system (CPS) with 40 replicate trataments. The soil resistance to penetration (PR) was measured using the Falkerbrand Electronic Pressure Compaction Meter PenetroLOG - PLG 1020, at a depth of 0,00 to $0 ; 40 \mathrm{~m}$, which was subdivided into eight layers of $0,05 \mathrm{~m}$ for evaluation. The adoption of no-tillage and conventional tillage systems caused oscillation in the soil mechanical resistance to penetration along the soil layers. In the CPS, a lower RP was observed when compared to the other treatment, at depth $0,00-0,10 \mathrm{~m}$. Differently, in the NTS, the sublayers of $0,15-0,25 \mathrm{~m}$ presented lower RP values and higher soil moisture. From the depth of 0,20 m both systems presented indicative of compacted layers of the soil.

\section{Revista Verde}

ISSN 1981-8203

Pombal, Paraíba, Brasil v. 14, n.1, jan.-mar, p.140-145, 2019

doi: $10.18378 /$ rvads.v14i1.5892 


\section{INTRODUÇÃO}

Com a evolução da colheita mecanizada e o crescente melhoramento de cultivares mais produtivas têm-se aumentado as áreas cultivadas (FACHIN et al., 2014). O uso de novas áreas agricultáveis para o plantio demanda igualmente maior número de máquinas e implementos modernos e de elevada capacidade operacional para ser empregado no campo, e atender a sua necessidade tecnológica (CONAB, 2013).

$\mathrm{Na}$ atividade agrícola trabalha-se a porção mais superficial do solo, a qual é chamada de camada arável (ALCÂNTARA et al., 2008). Esta é preparada para oferecer condições ideais para a semeadura, germinação, emergência e desenvolvimento das plantas (MACEDO et al., 2009). O preparo do solo é a primeira operação a ser realizada, pois compreende um conjunto de práticas que, quando usadas de forma adequada permitem alta produtividade da cultura (EMBRAPA, 2013). O sistema de plantio convencional (SPC) e o sistema de plantio direto (SPD) estão entre as principais formas de manejo do solo, e a escolha varia de acordo com a textura, estrutura e grau de compactação do solo, bem como de acordo com a disponibilidade de equipamentos e de recursos do produtor (NASCENTE et al., 2011).

O sistema de plantio direto baseia-se nos princípios da cobertura permanente, revolvimento mínimo do solo, rotação de culturas e adubação verde, podendo resultar na melhor eficiência em manter a qualidade física, química e biológica do solo e condições favoráveis ao desenvolvimento vegetal em decorrência da ausência de operações com máquinas para o preparo da área (LANZANOVA et al., 2010). Diferente disso, o sistema de plantio convencional, de maneira geral, envolve os preparos primário e secundário que consistem no revolvimento da camada superficial do solo com uso de equipamentos como o arado e a grade (PEREIRA; RODRIGUES, 2013).

Todavia, as máquinas e implementos agrícolas utilizados para as operações de preparo do solo estão cada vez maiores e mais pesados, e com o uso crescente do maquinário nos sistemas produtivos, o solo passou a receber maior pressão, e quando associada ao uso inadequado de acordo com as condições de umidade do solo, resulta no aumento da compactação e diminuição da produtividade das culturas (CORTEZ et al., 2017; FERRARI et al., 2018). A compactação do solo é caracterizada pelo aumento da densidade do solo, pelos altos valores de resistência do solo à penetração, redução da infiltração de água, distribuição e tamanho de poros no solo e pela diminuição de difusão dos gases e disponibilidade de nutrientes (VALADÃO et al.,
2015; SCAPINELLI et al., 2016). Dentre fatores como densidade, textura, matéria orgânica e umidade do solo, a resistência do solo à penetração é considerada a propriedade do solo adequada para expressar o grau de compactação existente no solo. Tornando-se fundamental tanto para recomendação de práticas de manejo do sistema de preparo mais adequado do solo, como para a avaliação dos efeitos na agricultura (SILVEIRA et al., 2010).

Existem formas para determinar a resistência do solo à penetração, dentre elas, a penetrometria é uma técnica que identifica as camadas que apresentam restrição ao desenvolvimento radicular das plantas (CAVALCANTE et al., 2011; MION et al., 2012). É uma técnica quantitativa muito utilizada devido à facilidade, rapidez e a possibilidade de se efetuar grande número de repetições para obtenção de dados (SILVEIRA et al., 2010). No entanto, esta é variável conforme a condição estrutural e conteúdo de água do solo no momento de sua avaliação (VALICHESKI et al., 2012).

$\mathrm{Na}$ ciência do solo muitos estudos recentes apontam para pesquisas voltadas para a avaliação da qualidade física dos solos em relação ao seu manejo (BROWN et al., 2018; CAMPOS et al., 2018), visto que esse tema é constante na literatura mundial em virtude das interferências na produtividade das culturas e sustentabilidade dos ecossistemas ligados ao solo (GUEDES et al., 2012). Com isso, tornam-se de grande importância os estudos científicos que avaliam a relação máquina-solo-planta (LIMA et al., 2013). Nesse sentido, o presente trabalho consiste na hipótese de que o sistema de manejo convencional do solo ocasiona maiores valores de RP em relação ao sistema de plantio direto.

Com isso, o presente trabalho teve como objetivo avaliar a resistência mecânica do solo à penetração utilizando a técnica da penetrometria, em dois sistemas de manejo do solo, convencional (SPC) e plantio direto (SPD).

\section{MATERIAL E MÉTODOS}

O experimento foi realizado na Universidade Federal Rural da Amazônia Campus de Parauapebas, localizada nas coordenadas geográficas $06^{\circ} 04^{\prime} 26^{\prime}$ ' latitude Sul, 49 49' 03" longitude Oeste, com altitude de $239 \mathrm{~m}$ e declividade variando de $2 \%$ a $3 \%$. O clima é classificado como Tropical úmido, tipo Am, na classificação de Köppen, no limite de transição para o $\mathrm{AW}$, com índice pluviométrico anual em torno de $2.000 \mathrm{~mm}$. O solo foi classificado conforme a EMBRAPA (2013), como Latossolo Vermelho-Amarelo, textura franca, cuja composição granulométrica consta na Tabela1.

Tabela 1. Análise granulométrica do solo nas profundidades de $0,00-0,20 \mathrm{~m} \mathrm{e} \mathrm{0,20} \mathrm{-} \mathrm{0,40} \mathrm{m.}$

\begin{tabular}{|c|c|c|c|c|c|}
\hline \multirow{3}{*}{$\begin{array}{l}\text { Profundidade } \\
\text { (m) }\end{array}$} & \multirow[b]{2}{*}{ Argila } & \multirow[b]{2}{*}{ Silte } & \multicolumn{2}{|c|}{ Areia } & \multirow{3}{*}{$\begin{array}{l}\text { Classe } \\
\text { Textural }\end{array}$} \\
\hline & & & Fina & Grossa & \\
\hline & \multicolumn{4}{|c|}{$\left(\mathrm{g} \mathrm{kg}^{-1}\right)$} & \\
\hline $0,00-0,20$ & 120 & 487 & 206 & 188 & Franca \\
\hline $0,20-0,40$ & 140 & 479 & 176 & 205 & Franca \\
\hline
\end{tabular}

Os dados de resistência do solo à penetração (RP) foram coletados no período de Junho à Setembro de 2014. A área do experimento totalizou $800 \mathrm{~m}^{2}(20 \times 40 \mathrm{~m})$ e a vegetação anterior à implantação dos sistemas de cultivo consistiu em pastagem de Brachiaria brizantha, estabelecida há onze anos. As práticas de preparo do solo adotadas na área do SPC foram uma aração e duas gradagens leves com o auxílio do trator da marca New Holland, 4 x 2 TDA, com 75 CV operando na $2^{\mathrm{a}}$ 
marcha reduzida com velocidade média de $6,0 \mathrm{~km} \mathrm{~h}^{-1}$ a 2.000 rpm. O delineamento experimental utilizado foi inteiramente casualizado, contendo dois sistemas de cultivo (SPD e SPC), nos quais foram mensurados aleatoriamente, 40 pontos de RP, em cada tratamento, totalizando 80 unidades experimentais.

Para análise da RP, utilizou-se o Medidor Eletrônico de compactação do solo por pressão. Para determinação de teor de água no solo, simultaneamente à mensuração da RP, foram coletadas amostras indeformadas de solo em pontos aleatórios da área, para cada tratamento, utilizando o trado holandês, nas profundidades de 0,00 - 0,20 m e 0,20 - 0,40 m. Utilizou-se o método termogravimétrico em laboratório quantificado segundo a norma NBR 6457/1986 - ABNT, representada pela Equação 1 .

$$
H=(M 1-M 2) /(M 2-M 3) \times 100
$$

Em que: $\mathrm{H}=$ teor de água no solo, em $\% ; \mathrm{M}_{1}=$ massa do solo úmido mais a massa do recipiente, em $\mathrm{g} ; \mathrm{M}_{2}=$ massa do solo seco mais a massa do recipiente, em $\mathrm{g} ; \mathrm{M}_{3}=$ massa do recipiente (cápsula metálica com tampa), em g.

Tabela 2. Teor de água no solo para os sistemas utilizados

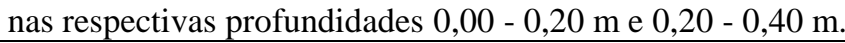

\begin{tabular}{ccc}
\hline \multirow{2}{*}{ Tratamentos } & $\begin{array}{c}\text { Profundidade } \\
(\mathrm{m})\end{array}$ & $\begin{array}{c}\text { TAS } \\
(\%)\end{array}$ \\
\hline \multirow{2}{*}{ SPC } & $0,00-0,20$ & 23,92 \\
& $0,20-0,40$ & 24,86 \\
\hline \multirow{2}{*}{ SPD } & $0,00-0,20$ & 25,90 \\
& $0,20-0,40$ & 26,57 \\
\hline
\end{tabular}

Os dados do penetrômetro foram tabulados no programa de computador fornecido pela fabricante do penetrômetro, denominado Compactação do Solo v.1.41. Os resultados de resistência mecânica do solo à penetração foram submetidos à análise de variância sendo as médias comparadas pelo teste de Tukey a $5 \%$ de probabilidade. A análise estatística foi realizada utilizando o software SISVAR (FERREIRA, 2011).

\section{RESULTADOS E DISCUSSÃO}

Na Tabela 3 observam-se os resultados da análise de variância da RP nos sistemas de manejo, onde foi observado maior RP superficial no SPD, e subsuperficial no SPC. Em ambos os tratamentos observa-se comportamento crescente da $\mathrm{RP}$ ao longo das camadas analisadas do SPD $(0,00-0,40 \mathrm{~m})$ e do SPC até os $0,30 \mathrm{~m}$, apresentando valores entre 0,017 e 2,58 $\mathrm{MPa}$, indicando a necessidade de monitoramento e o preparo em camadas sub superficiais. Estes resultados corroboram com os encontrados por Pereira et al. (2002), Bono et al. (2013), Ferrari et al. (2018) e Theodoro et al. (2018) que também constataram maiores valores de resistência à penetração com o aumento da profundidade, independente dos sistemas de cultivo estudados.

Nos sistemas avaliados, verifica-se diferença estatística a $5 \%$ de probabilidade nas profundidades de $0,00-0,05$ e $0,05-0,10 \mathrm{~m}$. O SPC apresentou menores valores de RP com médias de 0,017 e 0,366 MPa nas camadas supracitadas, respectivamente.

Tabela 3. Síntese da análise da variância para a RP (MPa) nos sistemas de manejo do solo em diferentes profundidades

\begin{tabular}{lccccccccc}
\hline $\begin{array}{c}\text { Fatores } \\
\text { Variação }\end{array}$ & de & $0,00-0,05$ & $0,05-0,10$ & $0,10-0,15$ & $\begin{array}{r}0,15-0,20 \\
(\mathrm{~m})\end{array}$ & $0,20-0,25$ & $0,25-0,30$ & $0,30-0,35$ & $0,35-0,40$ \\
\hline \multirow{2}{*}{$\begin{array}{l}\text { Sistema de Manejo } \\
\text { Valor de F }\end{array}$} & SPC & $0,017 \mathrm{~b}$ & $0,366 \mathrm{~b}$ & 1,320 & $2,212 \mathrm{a}$ & $2,435 \mathrm{a}$ & 2,513 & 2,511 \\
DMS & SPD & $0,049 \mathrm{a}$ & $0,621 \mathrm{a}$ & 1,322 & $1,666 \mathrm{~b}$ & $2,039 \mathrm{~b}$ & 2,374 & 2,522 & 2,516 \\
& & $5,01^{*}$ & $10,24^{*}$ & $0,00^{\mathrm{NS}}$ & $22,09^{* * *}$ & $9,80^{* *}$ & $1,36^{\mathrm{NS}}$ & $0,01^{\mathrm{NS}}$ & $1,66^{\mathrm{NS}}$ \\
CV (\%) & & 27,94 & 160,92 & 267,55 & 234,80 & 256,15 & 242,37 & 213,85 & 257,11 \\
\hline
\end{tabular}

Médias seguidas de mesma letra na coluna não diferem entre si pelo teste de Tukey para um nível de 5\% de probabilidade. SPC: Sistema Plantio Convencional; SPD: Sistema Plantio direto. ${ }^{\mathrm{NS}}$ : não significativo $(\mathrm{P}>0,05) ;{ }^{*}$ : significativo $(\mathrm{P} \leq 0,05) ;{ }^{* *}$ : significativo $(\mathrm{P} \leq 0,01)$; $\mathrm{CV}$ : coeficiente de variação $(\%)$.

Resultados semelhantes foram obtidos por Beutler et al (2001), Ortigara et al. (2014) e Tavares Filho et al. (2001) ao avaliarem a resistência do solo à penetração em Latossolo Vermelho sob diferentes cultivos, verificaram maiores valores de RP no SPD na camada mais superficial. Quando determinada pressão externa é aplicada ao solo por máquinas, ocorre um novo acomodamento ou disposição das partículas, diminuindo o espaço poroso do solo, resultando em incremento dos valores de resistência à penetração (STRECK et al., 2004).

Abaixo da camada superficial, nas camadas de 0,15 $0,20 \mathrm{~m}$ e $0,20-0,25 \mathrm{~m}$ houve diferença a $1 \%$ de probabilidade entre os valores de RP. No entanto, não foi verificada significância $(P>0,05)$ entre as médias de RP na camada de 0,10 - 0,15 m, tampouco nas camadas abaixo de 0,25 m. A oscilação nos valores de RP nos diferentes sistemas de manejo pode ser relacionado à pressão exercida no solo durante o tráfego de maquinário específico para cada sistema de manejo. No SPC a profundidade de trabalho em que os implementos revolvem a camada superficial durante o preparo do solo é até $0,20 \mathrm{~m}$ de profundidade, ocasionando valores de RP mais baixos, e normalmente os maiores valores encontram-se abaixo da camada trabalhada (CORTEZ et al., 2011).

Para as profundidades de $0,15-0,20$ e 0,20 - 0,25 m, observou-se comportamento da RP, nos sistemas de manejo, contrário às camadas superficiais. No caso em questão, o SPD apresentou menor resistência à penetração em relação ao SPC com valores de 1,666 MPa para camada de 0,15-0,20 m e 2,039 $\mathrm{MPa}$ para $0,20-0,25 \mathrm{~m}$. A resistência do solo à penetração é mais afetada pela variação dos conteúdos de sua umidade devida faixa do teor de água estar diretamente relacionada à capacidade do solo de suportar e permitir o trabalho do maquinário agrícola (PINTO FILHO et al., 2009; MERCANTE et al., 2003). O SPD apresentou uma porcentagem de umidade em torno de $8 \%$ superior ao encontrado no SPC, com $25,90 \%$ na camada de $0,0-0,20 \mathrm{~m}$ e $26,57 \%$ em 0,20 - 0,40 m. Essa condição do solo ocasiona 
diminuição das forças de coesão entre as partículas do solo e aumento do efeito lubrificante da água, ou seja, a RP apresenta relação inversa com o teor de umidade do solo (SILVA et al., 2006).

Esse resultado pode ser atribuído à cobertura vegetal do solo no SPD que mantém o teor de água e a temperatura do solo mais uniforme nas camadas mais superficiais devido ao impedimento ou diminuição da ação direta de fatores externos como a incidência de raios solares sobre a superfície do solo (LOSS et al., 2011). Em ambos os tratamentos, houve aumento no conteúdo de água ao longo das camadas do solo. Esse aumento deve-se à classe textural Franca do solo, a qual se insere como um fator determinante para o estado estrutural do solo e consequentemente para a sua capacidade de reter água nos poros nas camadas mais profundas.

Embora a umidade do solo esteja mais elevada nessas camadas em relação às outras profundidades, em ambos os tratamentos, foram mensuradas RP com valores entre 2,43 e 2,58 $\mathrm{MPa}$ na profundidade de 0,20 - 0,40 m. Em virtude de o solo ter atingido valores de RP superiores a 2,0 $\mathrm{MPa}$ nas camadas supracitadas, esses valores podem ser um indicativo de que, nesta profundidade, possa apresentar pé-de-grade devido ao tráfego de trator, semeadora ou gradagens sucessivas na mesma profundidade. LANZANOVA et al. (2007) e SILVA et al. (2002) relatam que um valor de resistência à penetração do solo acima de $2 \mathrm{MPa}$ pode estar relacionado às condições impeditivas para o crescimento das raízes e da parte aérea das plantas. Contudo, é necessário relacionar a resistência do solo à penetração com a aeração e com o potencial matricial de água do solo (SILVA et al., 2002).

Foloni et al. (2003) ao avaliarem o efeito da compactação sobre o desenvolvimento radicular de plantas de milho, observaram que uma camada compactada com resistência à penetração da ordem de $1,4 \mathrm{MPa}$ na camada subsuperficial do solo impede que o sistema radicular do milho atravesse essa camada e se desenvolva em profundidade. Ainda de acordo com o autor, espécies comumente utilizadas nos sistemas de rotação de culturas, como a soja e o milheto também mostram sensibilidade a valores semelhantes de RP.

$\mathrm{Na}$ figura 1 evidencia-se que o valor médio de RP para $0,10 \mathrm{~m}$ é similar e menor que $2 \mathrm{MPa}$ em ambos os tratamentos, sendo estes valores médios inferiores aos observados a partir de $0,15 \mathrm{~m}$, demonstrando assim que o maior grau de compactação localiza-se nesta faixa de profundidade. Ibiapina et al. (2014) também verificaram um aumento abrupto do valor de RP, após a camada de $0,15 \mathrm{~m}$ de profundidade, para o mesmo sistema de manejo saindo de menos de $1 \mathrm{MPa}$ para mais de $6 \mathrm{MPa}$ na profundidade de 0,30 m.

Segundo Cortez et al. (2011), valores elevados de resistência predominaram nas camadas abaixo de $0,30 \mathrm{~m}$ de profundidade, no entanto, neste trabalho observou-se, para todos os sistemas de manejo empregado, valores abaixo do limite citado.

A RP no sistema de plantio direto, apresenta-se consideravelmente baixa, equiparando-se aos obtidos por Bottega et al. (2011), trabalhando com variabilidade espacial da resistência do solo à penetração em um Latossolo Vermelho Distroférrico, observaram a predominância de valores entre 4,8 e 5,3 $\mathrm{MPa}$ nas respectivas profundidades $0,00-0,40 \mathrm{~m}$ em solo com umidade acima da faixa friável.
Girardello et al. (2014), em estudos sobre a resistência mecânica do solo à penetração também em Latossolo Vermelho sob sistema de plantio direto, obtiveram predominância de valores na faixa de 3,0 a 5,0 MPa na mesma profundidade do presente trabalho. Em avaliação da RP em sistemas de cultivo, Borges et al. (2004) obtiveram médias variando entre 2 e $3 \mathrm{MPa}$ no SPC, sendo um resultado esperado tendo-se em vista o revolvimento do solo e o tráfego de implementos sobre a superfície do terreno. Com isso, e pode-se inferir que os sistemas de manejo avaliados afetaram de modo similar.

Figura 1. Resistência mecânica do solo à penetração na profundidade de 0,00 - 0,40 m, em dois sistemas de manejo do solo, em Parauapebas, Pará.

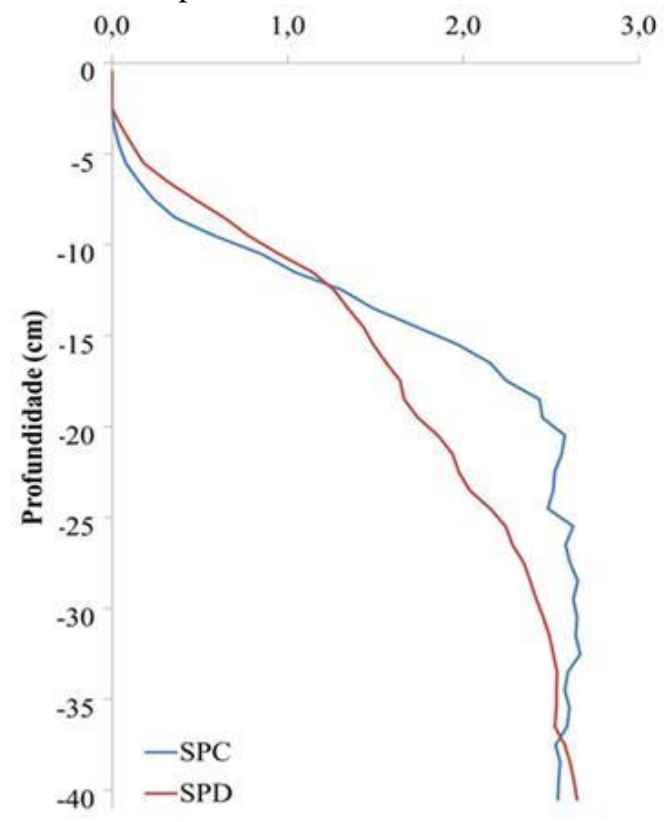

\section{CONCLUSÕES}

Os sistemas de manejo de solo causam modificações na estrutura do solo, provocando camadas com diferentes graus de compactação.

O sistema de plantio convencional ocasiona maiores alterações físicas no solo.

\section{REFERÊNCIAS}

ALCÂNTARA, F. A.; MADEIRA, R. N. Manejo do solo no sistema de produção orgânico de hortaliças. Circular Técnica, Brasília, DF, 2008.

BORGES, J. R.; PAULETTO, E. A.; SOUSA, R. O.; PINTO, L. F. S.; LEITZKE, V. W. Resistência à penetração de um Gleissolo submetido a sistemas de cultivo e culturas. Revista brasileira Agrociência, v. 10, n. 1, p. 83-86, 2004.

BONO, J. A. M.; MACEDO, M. C. M.; TORMENA, C. A. Qualidade física do solo em um Latossolo Vermelho da região Sudoeste dos Cerrados sob diferentes sistemas de uso e manejo. Revista Brasileira de Ciência do Solo, v. 37, p. 743753, 2013. 
BotTeGA, E. L.; BOtTEGA, S. P.; SILVA, S. A. QUEIROZ, D. M.; SOUZA, C. M. A.; RAFULL, L. Z. L. Variabilidade espacial da resistência do solo à penetração em um Latossolo Vermelho distroférrico. Revista Brasileira de Ciências Agrárias, v. 6, n. 2, p. 331-336, 2011.

BROWN, V.; BARBOSA, F. T.; BERTOL, I.; MAFRA, A L.; MUZEKA, L. M. Efeitos no solo e nas culturas após vinte anos de cultivo convencional e semeadura direta. Revista Brasileira de Ciências Agrárias. v. 13, n. 1, p1-7, 2018.

CAMPOS, S. A.; SOUZA, C. M.; GALVÃO, J. C. C.; NEVES, J. C. L. Atributos químicos e físicos de um Argissolo Vermelho-Amarelo Distrófico sob plantio direto. Revista Agrarian, v. 11, n. 41, p. 230-240, 2018.

CAPINELLI, A.; DEINA, F. R.; VALADÃO JUNIOR, D. D.; VALADÃO, F. C. A.; PEREIRA, L. B. Sistema radicular e componentes produtivos do girassol em solo compactado. Red de Revistas Científicas de América Latina y el Caribe. v. 75, n. 4, p. 474-486, 2016.

CAVAlCANTE, E. G. S.; ALVES, M. C.; SOUZA, Z. M.; PEREIRA, G. T. Variabilidade espacial de atributos físicos do solo sob diferentes usos e manejos. Revista de Engenharia Agrícola e Ambiental, v. 15, n. 3, p. 237-243, 2011.

CONAB, Companhia Nacional de Abastecimento Acompanhamento da safra brasileira de grãos - Safra 2013/14 - Segundo Levantamento, Brasília, v. 1, n. 2, p. 1-66, 2013.

CORTEZ, J. W.; ALVES, A. D. S.; MOURA, M. R. D.; OLSZEVSKI, N.; NAGAHAMA, H. J. Atributos físicos do Argissolo amarelo do semiárido nordestino sob sistemas de preparo. Revista Brasileira de Ciência do Solo, v. 35, p. $1207-$ 1216, 2011.

CORTEZ, J. W.; MAUAD, M.; SOUZA, L. C. F.; RUFINO, M. V.; SOUZA, P. H. N. Atributos agronômicos da soja e resistência à penetração em plantio direto e escarificado. Revista Engenharia Agrícola v. 37, n. 1, 2017.

EMBRAPA, Empresa Brasileira de Pesquisa Agropecuária. Sistema brasileiro de classificação de solos. 3. ed. Brasília, 2013. 353p

EMBRAPA, Empresa Brasileira de Pesquisa Agropecuária. Tecnologias de Produção de Soja na Região Central do Brasil. Embrapa Soja, Londrina, PR, 2013.

FACHIN, G. M.; JÚNIOR, J. B. D.; GLIER, C. A. S.; MROZINSKI, C. R.; COSTA, A. C. T.; GUIMARÃES ,V. F. Características agronômicas de seis cultivares de amendoim cultivadas em sistema convencional e de semeadura direta. Revista Brasileira de Engenharia Agrícola e Ambiental, v. 18, n. 2, p. 165-172, 2014.

FERRARI, J. M. S.; GABRIEL, C. P. C., SILVA, T. B. G.; MOTA, F. D.; GABRIEL FILHO, L. R. A., TANAKA, E. M. Análise da variabilidade espacial da resistência à penetração do solo em diferentes profundidades. Brazilian Journal of Biosystems Engineering v. 12, n. 2, p. 164-175, 2018.
FERREIRA, D. F. Sisvar: a computer statistical analysis system. Ciência e Agrotecnologia, v. 35, n. 6, p. 1039-1042, 2011.

FOLONI, J. S. S.; CALONEGO, J. C.; LIMA, S. L. Efeito da compactação do solo no desenvolvimento aéreo e radicular de cultivares de milho. Pesquisa Agropecuária Brasileira, v. 38, n. 8 , p. $947-953,2003$.

GIRARDELLO, V. C.; AMADO, T. J. C.; SANTI, A. L.; CHERUBIN, M. R.; KUNZ, J.; TEIXEIRA, T. G. Resistência à penetração, eficiência de escarificadores mecânicos e produtividade da soja em Latossolo Argiloso manejado sob plantio direto de longa duração. Revista Brasileira de Ciência do Solo, v. 38 p. $1234-1244,2014$.

GUEDES, E. M. S.; FERNANDES, A. R.; LIMA, H. V.; SERRA, A. P.; COSTA, J. R.; GUEDES, R. S. Impacts of different management systems on the physical quality of in amazonian oxisol. Revista Brasileira de Ciência do Solo, v. 36, p. 1269-1277, 2012.

IBIAPINA, T. V. B.; SALVIANO, A. A. C.; NUNES, L. A P. L; MOUSINHO, F. E. P; LIMA, M. G.; SOARES, L. M. S. Resistência à penetração e agregação de um Latossolo Amarelo sob monocultivo de soja e de eucalipto no cerrado do Piauí. Revista Científica, v. 42, n. 4, p. 411-418, 2014.

LANZANOVA, M. E., SILVEIRA, N. R.; LOVATO, T.; ELTZ, F. L. F.; AMADO,T. J.C. ; REINERT, D. J. Atributos físicos do solo em sistema de integração lavoura-pecuária sob plantio direto. Revista Brasileira Ciência do Solo, v. 31, p. 1131-1140, 2007.

LANZANOVA, M. E.; ELTZ, F. L. F.; NICOLOSO, R. S.; AMADO, T. J.; REINERT, D. J.; ROCHA, M. R.; Atributos físicos de um Argissolo em sistemas de culturas de longa duração sob semeadura direta. Revista Brasileira de Ciência do Solo, v. 33, p. 1333-1342, 2010.

LIMA, R. P.; LEÓN, M. J.; SILVA, A. R. Comparação entre dois penetrômetros na avaliação da resistência mecânica do solo à penetração. Revista Ceres, v. 60, n. 4, p. 577-581, 2013.

LOSS, A.; PEREIRA, M. G.; GIÁCOMO, S. G.; PERIN, A.; ANJOS, L. H. C. Agregação, carbono e nitrogênio em agregados do solo sob plantio direto com integração lavourapecuária. Pesquisa agropecuária brasileira, Brasília, v. 46, n. 10, p. 1269-1276, 2011.

MACEDO, J. R.; CAPECHE, L. C.; MELO, A. S. Recomendações de manejo e conservação de solo e água. Manual Técnico, Niterói, v. 20 p. 198-567, 2009.

MERCANTE, E.; URIBE-OPAZO, M. A.; SOUZA, E. G. Variabilidade espacial e temporal da resistência mecânica do solo à penetração em áreas com e sem manejo químico localizado. Revista Brasileira de Ciência do Solo, v. 27, p. 1149-1159, 2003.

MION, R. L.; NASCIMENTO, E. M. S.; SALES, F. A. L.; SILVA, S. F.; DUARTE, J. M. L.; SOUSA, B. M. 
Variabilidade espacial da porosidade total, umidade e resistência do solo à penetração de um Argissolo Amarelo. Revista Semina: Ciências Agrárias, v. 33, n. 6, p. 2057-2066, 2012.

NASCENTE, A. S.; KLUTHCOUSKI, J.; RABELO, R. R.; OLIVEIRA, P.; COBUCCI, T.; CRUSCIO, C. A. C. Desenvolvimento e produtividade de cultivares de arroz de terras altas em função do manejo do solo. Revista Pesquisa Agropecuária Tropical, v. 41, n. 2, p. 186-192, 2011.

ORTIGARA, C.; KOPPE, E.; LUZ, F. B.; BERTOLLO, A. M.; KAISER, D. R.; SILVA, V. R. Uso do solo e propriedades físico-mecânicas de Latossolo Vermelho. Revista Brasileira de Ciência do Solo, v. 38, p. 619-626, 2014.

PEREIRA, J. O.; SIQUEIRA, J. A. C., URIBE-OPAZO, M. A.; SILVA, S. L. Resistência do solo resistência do solo à penetração em função à penetração em função do sistema de cultivo do sistema de cultivo e teor de água do solo. Revista Brasileira de Engenharia Agrícola e Ambiental, v. 6, n. 1, p. 171-174, 2002.

PEREIRA, L. S.; RODRIGUES, A. M. Sistemas de Manejo de Cultivo Mínimo e Convencional: Análise Temporal da Dinâmica Hidrológica do Solo e da Variação Produtiva em Ambiente Serrano. Revista Brasileira de Geografia Física v. 6, n. 6, p. 1658-1672, 2013.

PINTO FILHO, J. L. O.; DANTAS, V. B.; PEREIRA, J. O. Suscetibilidade de compactação do solo em diferentes teores de umidade e matéria orgânica. Revista Verde de Agroecologia e Desenvolvimento Sustentável, v. 4, n. 2, p. 76-84, 2009

STRECK, C. A.; REINERT, D. J.; REICHERT, J. M.; KAISER, D. R. Modificações em propriedades físicas com a compactação do solo causada pelo tráfego induzido de um trator em plantio direto. Ciência Rural, v. 34, n. 3, p. 755-760, 2004.

SILVA, V. R.; REICHERT, J. M.; REINERT, D. J. Variabilidade espacial da resistência do solo à penetração em plantio direto. Ciência Rural, v. 34, n. 2, p.3 99-406, 2004.

SILVEIRA, D. C.; MELO FILHO, J. F.; SACRAMENTO, J. A. A. S.; SILVEIRA, E. C. P. Relação umidade versus resistência à penetração para um Argissolo Amarelo Distrocoeso no recôncavo da Bahia. Revista Brasileira de Ciência do Solo, Viçosa, v. 34, n. 3, p. 659-667, 2010.

TAVARES FILHO, J.; BARBOSA, G. M. C.; GUIMARÃES, M. F.; I. C. B. FONSECA. Resistência do solo à penetração e desenvolvimento do sistema radicular do milho (Zea mays) sob diferentes sistemas de manejo em um Latossolo roxo. Revista Brasileira de Ciência do Solo, v. 25, p.725-730, 2001.

THEODORO, G. F.; GOLIN, H. O.; REZENDE, R. P.; ABREU, V. L. S.; SILVA, M. S. Influência de sistemas de preparo na manutenção da palhada e resistência do solo à penetração. Revista de Agricultura Neotropical, v. 5, n. 2, p. 25-30, 2018.

VALADÃO, F. C. ASSIS.; WEBER, O. L. S.; VALADÃO JÚNIOR, D. D.; SCAPINELLI, A.; DEINA, F. R.; BIANCHINI, A. adubação fosfatada e compactação do solo: sistema radicular da soja e do milho e atributos físicos do solo. Revista Brasileira de Ciência do Solo, v. 39, p. 243-255, 2015.

VALICHESKI, R. R.; GROSSKLAUS, F.; STÜRMER, S. L. K.; TRAMONTIN, A. L.; BAADE, E. S. A. S. Desenvolvimento de plantas de cobertura e produtividade da soja conforme atributos físicos em solo compactado. Revista Brasileira de Engenharia Agrícola e Ambiental, v. 16, n. 9, p. 969-977, 2012. 